\title{
Education Research: The medical student perspective on challenging conversations
}

Rheaya Willis, BA, Roy E. Strowd, MD, Mary C. Barks, MA, Rachel E. Salas, MD, MEdHP, Charlene E. Gamaldo, MD, and Monica E. Lemmon, MD

Neurology ${ }^{\circledR}$ 2020;95:226-230. doi:10.1212/WNL.0000000000009261

\section{Abstract}

\section{Objective}

Medical students experience difficult conversations with patients during clinical clerkships. This study aimed to characterize barriers to and opportunities for learning in the setting of challenging conversations.

\section{Methods}

Neurology clerkship medical students were enrolled prospectively in a concurrent nested mixed methods study. Qualitative data were collected using a postclerkship survey and semistructured focus groups. Students were asked to reflect on challenging conversations they experienced with patients and to identify the top reasons why conversations were challenging. Responses were analyzed using directed content analysis.

\section{Results}

A total of 159 medical students were enrolled (MS2: $\mathrm{n}=35$ [22\%]; MS3: $\mathrm{n}=97$ [61\%]; MS4: $\mathrm{n}$ $=27[17 \%])$. Three themes of difficulty were identified in survey and focus group data: (1) tough clinical realities: how the clinical environment makes conversations challenging; (2) communication skill needs: the difficulty of finding the words to say; and (3) navigating emotions: of patients, clinicians, and students themselves. Tough clinical realities were cited by over two-thirds of students in all years (MS2: $\mathrm{n}=30$ [86\%]; MS3: $\mathrm{n}=74$ [76\%]; MS4: $\mathrm{n}=23$ [85\%]). Communication skills needs were cited most frequently by third-year students (MS2: $\mathrm{n}=15[43 \%]$; MS3: $\mathrm{n}=55$ [57\%]; MS4: $\mathrm{n}=10[37 \%])$. Students early in training were more likely to cite difficulty navigating emotions (MS2: $\mathrm{n}=28[80 \%]$; MS3: $\mathrm{n}=71[73 \%]$; MS4: $\mathrm{n}=$ $19[70 \%])$.

\section{Conclusions}

Medical students frequently observe and participate in challenging conversations with patients. Here, students identified what makes these conversations most difficult. Communication curricula should leverage clinical communication encounters, prepare students for inherent clinical realities, and help students navigate emotions in the health care setting.
Correspondence

R. Willis

Rheaya.willis@duke.edu

From the Duke University School of Medicine (R.W.), Durham, NC; Department of Neurology (R.E. Strowd, R.E. Salas, C.E.G., M.E.L.), Johns Hopkins Medicine, Baltimore, MD; Department of Neurology (R.E. Strowd), Wake Forest School of Medicine, Winston-Salem, NC; Duke-Margolis Center for Health Policy (M.C.B., M.E.L.), Duke University; and Department of Pediatrics (M.E.L.), Duke University Medical Center, Durham, NC.

Go to Neurology.org/N for full disclosures. Funding information and disclosures deemed relevant by the authors, if any, are provided at the end of the article. 
Communication is the foundation for the doctor-patient relationship and a fundamental skill in medical education., Difficult conversation skills are often taught with standardized patient encounters. Many students will have their first real-life experiences with difficult conversations during their clinical rotations. Over half of medical students report directly participating in a difficult conversation during their clinical year ${ }^{3,4}$ and as many as $29 \%$ of residents first delivered bad news to a patient during medical school. ${ }^{5}$

In neurology clerkships, medical students frequently observe and participate in challenging conversations with patients. ${ }^{4}$ In a prior study, we found that these encounters are valuable educational opportunities for students to gain real-time experience in communication skills, and that the difficult nature of these conversations presents both barriers to, and unique opportunities for, communication skills instruction. ${ }^{4}$ This study was performed to understand the medical student perspective of participating in and observing challenging conversations, in order to inform future curricular design.

\section{Methods}

\section{Study procedures}

Data were collected as part of a cross-sectional concurrent nested mixed-methods study. ${ }^{4}$ Medical students at Johns Hopkins completing a required 4-week neurology core clerkship between August 2014 and March 2016 were eligible. At clerkship end, students were asked to reflect on challenging conversations they had encountered, including conversations about new disability, poor prognosis, uncertainty, terminal diagnosis, and end-of-life care. Most students $(\mathrm{n}=117[73 \%])$ reported having experienced at least one difficult conversation during the neurology clerkship; in focus groups, students acknowledged that they underreported their conversation exposure due to time burden. ${ }^{4}$ In surveys, students were asked to describe the top 3 reasons conversations may be difficult. A subset of students participated in semi-structured focus groups, which included a group discussion of what factors make communication encounters challenging.

\section{Data analysis}

Focus groups were audio-recorded and transcribed. Study team members derived code labels inductively from focus group and survey data. All survey responses were analyzed by directed content analysis, ${ }^{6}$ utilizing NVivo software (version 12). Two coders (R.W., M.C.B.) coded survey responses; $15 \%$ of responses were coded by both coders to ensure adequate interrater reliability. ${ }^{7}$ Interrater reliability was assessed with Cohen kappa. ${ }^{8}$

\section{Standard protocol approvals, registrations, and patient consents}

This study was reviewed and exempted by the Johns Hopkins Medicine institutional review board.

\section{Data availability}

Anonymized data will be shared by request with qualified investigators.

\section{Results}

A total of 159 medical students were enrolled; 158 completed the survey. Respondents included students in their second ( $\mathrm{n}$ $=35[22 \%])$, third $(n=97[61 \%])$, and fourth $(n=27[17 \%])$ years. Median age was 26 (range 23-37). Seventy-seven respondents (48\%) were female, 80 (50\%) were male, and 2 $(<2 \%)$ identified as a gender not otherwise specified.

Of the reasons students provided for why conversations were difficult, 3 themes were identified: (1) tough clinical realities: students perceived these encounters as high stakes and described the content of conversations, such as poor prognosis and prognostic uncertainty, as inherently difficult; (2) communication skills needs: students identified the challenges of avoiding jargon, of finding the right words to say, and of balancing honesty with the provision of hope; (3) navigating emotions: students described witnessing intricate emotional reactions: from patients, from clinicians, and within themselves. Students emphasized the difficulty of predicting and responding to patient emotions (table). Kappa was $>0.8$ for all themes. Responses were similar between sexes. Each theme was represented by students in all medical school years.

Tough clinical realities were cited by over two-thirds of students in all years (MS2: $\mathrm{n}=30$ [86\%]; MS3: $\mathrm{n}=74[76 \%]$; MS4: $\mathrm{n}=23$ [85\%]). Communication skills needs were cited most frequently by third-year students and least by fourthyear students (MS2: $\mathrm{n}=15$ [43\%]; MS3: $\mathrm{n}=55$ [57\%]; MS4: $\mathrm{n}=10[37 \%])$. Students early in training were more likely to cite difficulty with navigating emotions (MS2: $\mathrm{n}=28$ [80\%]; MS3: $\mathrm{n}=71[73 \%]$; MS4: $\mathrm{n}=19$ [70\%]).

\section{Tough clinical realities $(n=128[81 \%$ of total respondents])}

\section{Conversation content}

"The bottom line is that giving and discussing bad news is not a fun
experience, nor the reason that most of us go into medicine. But it is
part of the career." —Second-year student

Students described the content of these conversations as challenging. The most cited reason was the inherent difficulty of delivering bad news. They iterated that bad news is not only difficult to receive, but difficult to bear. Students identified poor prognosis as a type of bad news that is particularly difficult to disclose and discuss. They cited several poor prognoses: new disabilities, terminal diagnoses, comatose states, and conditions with few treatment options.

Many students cited uncertainty in diagnosis or prognosis as a primary challenge. Students reflected that this uncertainty 
Table Representative student quotes

\begin{tabular}{|c|c|}
\hline Topic & Quotes \\
\hline \multicolumn{2}{|c|}{$\begin{array}{l}\text { Tough clinical realities }(n=128[81 \% \text { of respondents]: MS2, } \\
n=30[86 \%] ; M S 3, n=74[76 \%] ; M S 4, n=23,[85 \%]\end{array}$} \\
\hline Conversation content & $\begin{array}{l}\text { "Conversations are difficult because often we are giving the patient news about an } \\
\text { uncertainty or unknown diagnosis, prognosis, or outcome. This type of news is } \\
\text { unsettling and unsatisfying, and answering questions is very difficult when there just } \\
\text { aren't any concrete answers to provide."-fourth-year student } \\
\text { "It is not something that a physician would like to tell the patient and not something that } \\
\text { a patient wants to hear. In cases where the disease will be progressive, it is also } \\
\text { challenging to convey that, even with the proper treatment, the disease will continue to } \\
\text { get worse over time."- third-year student }\end{array}$ \\
\hline High stakes & $\begin{array}{l}\text { "Sudden change in one's life that throws their life plans and goals into chaos. It impacts } \\
\text { more than the patient and includes many people like spouse or child."-third-year } \\
\text { student } \\
\text { "It is also more challenging when patient families are present and disagree with each } \\
\text { other about the next steps in treatment for a patient if the patient is not able to } \\
\text { communicate."- third-year student }\end{array}$ \\
\hline
\end{tabular}

Communication skills needs $(\mathrm{n}=81[51 \%$ of respondents]: MS2, $n=15$ [43\%]; MS3, $n=55$ [57\%], MS4: $n=10$ [37\%]

\section{Right things to say}

"Conveying information effectively. Being sensitive to patient's educational background. Making sure patients fully understand the difficult [conversation]."-fourth-year student

"Trying to provide medical information in a way that is neither too simplified [n]or too complicated."-second-year student

Balancing hope and honesty

"In a hopeless situation, you yourself want to see hope."- third-year student "Balance the line between being truthful and optimistic."-third-year student

Lack of experience

"Right now as a medical student, one of the hardest parts is that I don't have the knowledge to answer tough questions. I think if I had more clinical experience and knowledge, then I could feel more comfortable and just focus on how to best speak to my patients."-second-year student

"I don't feel like I have enough knowledge base to tell a patient everything they're going to want to know about any given difficult diagnosis and I want them to at least feel like they can rely on me during this difficult and turbulent time in their lives."-third-year student

Navigating emotions $(n=119[75 \%$ of respondents]: MS2, $n=28$

[80\%], MS3: n=71 [73\%]; MS4, n=19 [70\%]

Patient emotion

"I don't know how to console people. I don't like sounding fake by saying platitudes when something devastating has happened."-second-year student

"Emotions are tense and patients' families can become very upset if the situation is unexpected."-third-year student

Student and provider emotion

"There is often frustration/sadness on the part of the providers that they couldn't have done more to prevent the negative outcome (and they feel the need to mask this and act 'normal')."-third-year student

"Being able to appropriately control my own emotions during the encounter, and remain calm, relaxed and collected."-fourth-year student

could leave clinicians unable to provide concrete answers to patients' questions.

\section{High stakes}

"We are responsible for conveying information that may change someone's life forever"

—Second-year student

Students described the high stakes and responsibility involved in these conversations, iterating that patients' lives could be abruptly and drastically changed. The stakes were heightened by conflict between family members, time limitations, and the challenge of coordinating multiple medical teams. Students described that in these high-stakes situations, it can be difficult to anticipate and honor patients' values; for example, some noted that medical outcomes, statistics, and probabilities could seem discordant with what patients found meaningful.

\section{Communication skills needs ( $n=81[51 \%$ of total respondents])}

\section{The right things to say}

"Having difficult conversations requires a lot of tactfulness in terms of how that information is delivered, as the delivery is key for framing the patient's understanding and perspective."

$$
\text { — Third-year student }
$$

Students described difficulty in choosing the right words. They reflected that it can be difficult to meaningfully inform patients of relevant medical information without being 
overwhelming. Students perceived that communicating well requires a depth of knowledge and experience. They noted that it can be challenging to avoid jargon and reflected how a patient's or caregiver's educational background and emotional state likely influence medical comprehension.

\section{Balancing hope and honesty}

"You need a good balance between giving accurate information and not removing all hope from the family."

—Third-year student

Students described difficulty in balancing the need for honesty with the desire to provide hope. They acknowledged wanting to sugarcoat their words, or to sacrifice directness and honesty in favor of having less of an emotional impact. They perceived that clinicians' words had the power to instill or remove hope from patients; one student wrote that clinicians preferred to find and communicate the "silver lining."

\section{Lack of experience}

"Health care providers and medical students are not trained enough in how to have difficult conversations."

—Second-year student

Students reported that both they and practicing physicians lacked experience and training in challenging conversations. Students described a lack of exposure to challenging conversation curricula. One believed that students lacked exposure to challenging conversations because clinicians seemed to want to shelter them from these encounters. Students also reported feeling hindered by their lack of medical knowledge and clinical experience, saying that being new to medicine made them feel less prepared and capable of engaging in such discourse.

\section{Navigating emotions $(n=119[75 \%$ of total respondents])}

\section{Student and clinician emotion}

\section{"We have always been taught to heal, not how to deal with those we cannot heal."}

$$
\text { - Third-year student }
$$

Students similarly described their emotional reactions, as well as the emotions they perceived clinicians experience. They described sadness and guilt, particularly when delivering bad news. Students reported feeling uncomfortable with certain topics, which some attributed to their lack of training as a facilitator of challenging conversations. Some students described imagining themselves in the patients' shoes. Students discussed feeling helpless and inadequate and identified the challenges associated with being unable to heal patients. They described feeling responsible for patients' emotional and medical well-being.

\section{Patient emotion}

\begin{abstract}
"It is not always easy to predict how a patient or their family will respond. Although you may start off these conversations with a plan of how it will go, you need to adapt and adjust as the conversation goes on."
\end{abstract}

-Second-year student
Many students cited patient emotions as reasons for conversation difficulty. They described emotions they witnessed patients exhibit or imagined patients experiencing. Students discussed patients seeming fearful, angry, and helpless, particularly when clinicians presented uncertain prognostic outcomes. Students felt unable to predict how patients would react in emotional clinical encounters. They discussed the importance of clinicians acknowledging and responding to patients' emotions. Students listed several types of responses, including offering empathy, putting patients at ease, and giving patients space to process.

\section{Discussion}

Students identified 3 fundamental challenges present in communication encounters: inherently tough clinical realities, deficits in communication skills, and the need to navigate difficult emotions. Differences existed by year of training, likely reflecting the evolution of roles and challenges experienced by trainee level. These results suggest that didactic instruction in the absence of clinical context incompletely addresses communication skills and challenges. We highlight 3 ways these findings can be used to inform educational interventions and curricular design.

First, students described the inherent challenges of the clinical encounter when delivering bad news, relaying poor prognosis, or discussing medical uncertainty. They described busy wards, time constraints, and high stakes. While some clinical realities are difficult to modify, these complex conversations with patients offer real-time opportunities for student discussion and learning. Curricula should incorporate preconversation planning sessions, where clinicians guide learners in preparing for challenging clinical discussions. ${ }^{4}$ In preconversation planning sessions, learners and clinicians can discuss how clinical realities may influence the goals and context of upcoming conversations.

Second, students described concrete deficits in communication skills training. Students indicated that communication skills education should prioritize word choice and finding balance between honesty and the provision of hope. During preconversation planning sessions, students may benefit from generating a communication differential: multiple ways to frame or conduct the conversation, ranked based on appropriateness and anticipated effectiveness. Third-year students may benefit the most from such interventions, as they most frequently cited communication skills needs.

Finally, students were challenged to navigate difficult emotions. These findings suggest that communication curricula should include strategies for anticipating patient reactions, responding to patient emotion, and managing students' own emotional experiences. Following a difficult conversation, debriefing sessions can be valuable in promoting learning. 4 
Facilitators should guide learners through the 3 phases of debriefing: description of the event, analysis of participants' emotional involvement, and application to other encounters. ${ }^{10}$

Learners can be asked (1) what they observed, (2) what went as expected, (3) what was surprising, (4) how they felt, and (5) what they will take away from the experience. This intervention should especially be considered for students earlier in training, as these students most frequently cited the difficulties of navigating emotions.

There are limitations to this study. Student and patient characteristics that were not measured, such as prior communication training and experience, race, ethnicity, and language barriers between clinicians and patients, may influence the stated themes, and should be targets of future study. Unique characteristics of the site, such as the school's communication curricula or acuity of the patients served, could have affected students' experiences. Whereas the findings are broadly applicable to multiple disciplines, other clerkships may offer different educational opportunities. The challenges identified may be exacerbated in the field of neurology, which disproportionately cares for patients with life-altering and life-limiting illness. Future studies should investigate the student experience in other clerkships, and also the experiences of residents, fellows, and attendings.

This work offers unique insight into medical students' experiences of challenging conversations and of barriers to communication skills instruction in clinical settings. These findings can be leveraged to improve and refine communication skills curricula, in order to better prepare future physicians for challenging conversations with patients and families.

\section{Study funding}

No targeted funding reported.

\section{Disclosure}

R. Willis reports no disclosures. R.E. Strowd reports grants from the National Cancer Institute, Conquer Cancer Foundation of the American Society of Clinical Oncology, Southeastern Brain Tumor Foundation, and Jazz Pharmaceuticals; has received compensation for scientific consulting from Innocrin Pharmaceuticals, Novocure, and Monteris Medical unrelated to this manuscript; and serves as Deputy Editor of the Resident \& Fellow Section of Neurology ${ }^{\circledR}$. M.C. Barks reports no disclosures. R.E. Salas reports receiving royalties from Up-to-Date. C. Gamaldo reports receiving royalties from Up-to-Date and is a consultant with Jazz Pharmaceuticals. M.E. Lemmon reports grants from the
National Institute of Neurologic Disorders and Stroke of the NIH (K12NS098482) and the Derfner Foundation. Go to Neurology.org/N for full disclosures.

Appendix Authors

\begin{tabular}{lll}
\hline Name & Location & Contribution \\
\hline $\begin{array}{l}\text { Rheaya } \\
\text { Willis, BA }\end{array}$ & Duke University, & $\begin{array}{l}\text { Analysis and interpretation of } \\
\text { the data, drafting and revising } \\
\text { the manuscript for intellectual } \\
\text { content }\end{array}$ \\
\hline
\end{tabular}

\begin{tabular}{|c|c|c|}
\hline $\begin{array}{l}\text { Roy E. } \\
\text { Strowd, MD }\end{array}$ & $\begin{array}{l}\text { Wake Forest School of } \\
\text { Medicine, Winston- } \\
\text { Salem, NC }\end{array}$ & $\begin{array}{l}\text { Design and conceptualization of } \\
\text { the study, major role in the } \\
\text { acquisition of data, } \\
\text { interpretation of the data, } \\
\text { revising the manuscript for } \\
\text { intellectual content }\end{array}$ \\
\hline $\begin{array}{l}\text { Mary C. } \\
\text { Barks, MA }\end{array}$ & $\begin{array}{l}\text { Duke University, } \\
\text { Durham, NC }\end{array}$ & $\begin{array}{l}\text { Analysis and interpretation of } \\
\text { the data, revising the } \\
\text { manuscript for intellectual } \\
\text { content }\end{array}$ \\
\hline $\begin{array}{l}\text { Rachel E. } \\
\text { Salas, MD, } \\
\text { MEdHP }\end{array}$ & $\begin{array}{l}\text { Johns Hopkins } \\
\text { Medicine, Baltimore, } \\
\text { MD }\end{array}$ & $\begin{array}{l}\text { Design and conceptualization of } \\
\text { the study, major role in the } \\
\text { acquisition of data, revising the } \\
\text { manuscript for intellectual } \\
\text { content }\end{array}$ \\
\hline $\begin{array}{l}\text { Charlene } \\
\text { Gamaldo, } \\
\text { MD }\end{array}$ & $\begin{array}{l}\text { Johns Hopkins } \\
\text { Medicine, Baltimore, } \\
\text { MD }\end{array}$ & $\begin{array}{l}\text { Design and conceptualization of } \\
\text { the study, major role in the } \\
\text { acquisition of data, revising the } \\
\text { manuscript for intellectual } \\
\text { content }\end{array}$ \\
\hline $\begin{array}{l}\text { Monica E. } \\
\text { Lemmon, } \\
\text { MD }\end{array}$ & $\begin{array}{l}\text { Duke University, } \\
\text { Durham, NC }\end{array}$ & $\begin{array}{l}\text { Design and conceptualization of } \\
\text { the study, major role in the } \\
\text { acquisition of data, analysis and } \\
\text { interpretation of the data, } \\
\text { revising the manuscript for } \\
\text { intellectual content }\end{array}$ \\
\hline
\end{tabular}

\section{References}

1. Anderson MB, Cohen J, Hallock J, Kassebaum D, Turnbull J, Whitcomb M. Learning objectives for medical student education: guidelines for medical schools: report I of the Medical School Objectives Project. Acad Med 1999;74:13-18.

2. ACGME. Common Program Requirements. 2017. Available at: acgme.org/WhatWe-Do/Accreditation/Common-Program- Requirements. Accessed September 26, 2019.

3. Makoul G, Zick A, Aakhus M, Neely K, Roemer P. Using an online forum to encourage reflection about difficult conversations in medicine. Patient Edu Couns 2010; 79:83-86.

4. Lemmon M, Gamaldo C, Salas RM, Saxena A, Cruz T, Strowd R. Education Research: difficult conversations in neurology: lessons learned from medical students. Neurology 2018;90:93-97.

5. Orlander J, Fincke BG, Hermanns D, Johnson G. Medical residents' first clearly remembered experiences of giving bad news. J Gen Intern Med 2002;17:825-840.

6. Miles M, Huberman AM. Qualitative Data Analysis: An Expanded Sourcebook. 2nd ed. Thousand Oaks, CA: SAGE Publications; 1994.

7. Burla L, Knierim B, Barth J, Liewald K, Duetz M, Abel T. From text to codings: intercoder reliability assessment in qualitative content analysis. Nurs Res 2008;57: $113-117$.

8. Landis JR, Koch G. The measurement of observer agreement for categorical data. Biometrics 1977;33:159-174.

9. Bullard $\mathrm{M}$, Weekes A, Cordle R, et al. A mixed-methods comparison of participant and observer learner roles in simulation education. AEM Edu Train 2019;3:20-32.

10. Fanning R, Gaba D. The role of debriefing in simulation-based learning. Simul Healthc $2007 ; 2: 115-125$. 


\section{Neurology}

\section{Education Research: The medical student perspective on challenging conversations}

Rheaya Willis, Roy E. Strowd, Mary C. Barks, et al.

Neurology 2020;95;226-230 Published Online before print April 9, 2020

DOI 10.1212/WNL.0000000000009261

\section{This information is current as of April 9, 2020}

\section{Updated Information \& Services}

References

Citations

Subspecialty Collections

Permissions \& Licensing

Reprints including high resolution figures, can be found at: http://n.neurology.org/content/95/5/226.full

This article cites 8 articles, 1 of which you can access for free at: http://n.neurology.org/content/95/5/226.full\#ref-list-1

This article has been cited by 2 HighWire-hosted articles: http://n.neurology.org/content/95/5/226.full\#\#otherarticles

This article, along with others on similar topics, appears in the following collection(s):

Methods of education

http://n.neurology.org/cgi/collection/methods_of_education

Prognosis

http://n.neurology.org/cgi/collection/prognosis

Information about reproducing this article in parts (figures,tables) or in its entirety can be found online at:

http://www.neurology.org/about/about_the_journal\#permissions

Information about ordering reprints can be found online:

http://n.neurology.org/subscribers/advertise

Neurology ${ }^{\circledR}$ is the official journal of the American Academy of Neurology. Published continuously since 1951, it is now a weekly with 48 issues per year. Copyright () 2020 American Academy of Neurology. All rights reserved. Print ISSN: 0028-3878. Online ISSN: 1526-632X.

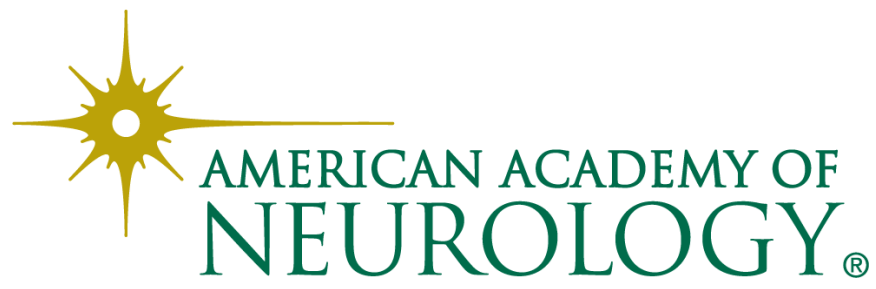

